\title{
Pattern and determinants of overweight and obesity among future physicians
}

\author{
Basu M 1, Das P2, Dhar G33, Datta S4, Chattopaddhyay S5, Bagchi S6, Pal R7
}

${ }^{1}$ Associate Professor, Community Medicine, IPGMER, Kolkata

${ }^{2}$ Associate Professor, Community Medicine, College of Medicine \& Sagore Dutta Hospital, Kolkata

${ }^{3}$ Associate Professor, Community Medicine, Swasthyabhavan, Kolkata

${ }^{4}$ Assistant Professor, Community Medicine, IPGMER, Kolkata

${ }^{5}$ Associate Professor, Community Medicine, IPGMER, Kolkata

6 Professor, Community Medicine, NRS Medical College

${ }^{7}$ Additional Professor, Community Medicine and Family Medicine, AIIMS, Jodhpur, Rajasthan

\section{Chief Editor}

Dr. Indrajit Banerjee

Technical Editor

Dr. Nishida Chandrasekharan

Formatting Editor

Dr. Indrajit Banerjee

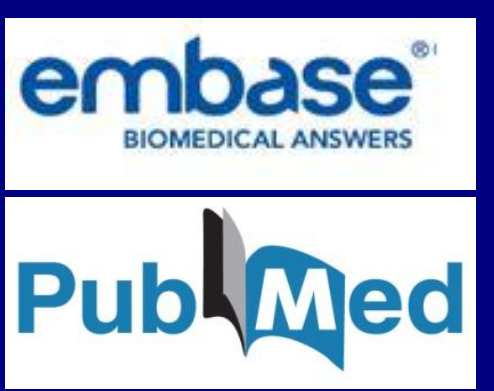

\section{This title is indexed in SciVerse Scopus \\ Improving research results through analytical power}

\section{Original Article}

\section{Corresponding Author}

Dr. Palash Das M.D

Associate Professor, Community Medicine

College of Medicine \& Sagore Dutta Hospital, Kolkata

E-mail: palashdasdr@gmail.com

\section{Abstract}

\section{Background}

Overweight including obesity is a leading cause of present day morbidity and kills more people than underweight. Keeping this background in mind this study had been conducted to establish the pattern of overweight and obesity in the midst of undergraduate medical group and to find out the association of overweight (plump) and obesity with probable hazardous factors.

\section{Materials and Methods}

This descriptive observational study had been conducted among undergraduate medical group for the duration of May to June 2011. Simple random sampling was adopted to select the students under study. A pretested, predesigned self-administered questionnaire was utilized for data collection. Body Mass Index (BMI) was assessed through weight and height and acted as forecaster of heavy figure and or obesity. Overweight and or obesity were analyzed to see the association with certain socio-demographic variables, dietary habits, family history of overweight and or obesity, life style issues, computer use etc. After collection of data, these were analyzed using tabulation, proportion and Chi square through Epi-Info software. 
Results

The study subjects were young adults. The general pattern of overweight (plump) and obesity was 18.0 percent and 4.0 percent respectively. Overweight and or obesity was found significantly high among male students, fast food and soft drinks takers, low takers of fruits and vegetables, alcohol consumers, students with lack of exercise and family history of obesity. Overweight and obesity were not found associated with type of diet (vegetarian or non-vegetarian) and smoking.

\section{Conclusion}

Presence of probable associated factors with regard to overweight (plump) and obesity exists amid medical undergraduate pupils.

Keywords: Overweight and obesity, undergraduate medical student, West Bengal

\section{Background}

Overweight and obesity are the leading cause of morbidity and kills more people than underweight; once a disease of high income countries is on the rise in developing countries, particularly in urban settings ${ }^{1}$. The associated factors with overweight and obesity are increasing age, feminine gender, municipal residence, being educated, having a elevated socio-economic status, genetic predisposition, dietary habits, amalgamation of an disproportionate nutrient intake for example fast food, high yielding drinks, high intake of meat, sedentary life, changes in lifestyle, addiction, lack of physical activity and the socio-cultural environment including stress ${ }^{2}$. Changes in socio-economic status possessed a considerable effect on physical activity with the accessibility of effortless transport, the easy use of electrical residencial appliances, more participation in studies and office job, lengthy period in watching small screen and by means of the internet. Obesity related morbidities include $\mathrm{CHD}$, high blood pressure, stroke, some types of cancers, type 2 DM, gall-bladder diseases, lipid problems, inflammation of joints, gout and lung diseases, including respiratory distress during sleep. The obese suffers from societal bias, chauvinism and unfairness ${ }^{2-5}$. WHO's Action Plan for Global Strategy for Prevention and Control of Non communicable Diseases provides a roadmap to establish and strengthen initiatives for the surveillance, prevention and management of non communicable diseases, including obesity which tells that Curbing the global obesity epidemic requires a population-based multisectoral, multidisciplinary, and culturally relevant approach ${ }^{6}$.

Obesity has already reached outbreak proportions in Indian adults in the new millennium by way of more than 10 percent are overweight and obese; five percent morbid obese; higher in women; common in old age, in urban welleducated and those in the highest wealth quintile ${ }^{7}$. There is lack of published literatures that supplied the information on the frequency of obesity among Indian medical pupils and medical professionals. Though health personnel including medical students are developers and influencing models for healthy way of life, studies in many places suggest that high weight is a crisis among them also ${ }^{8}$. In this context, we aimed to establish the occurrence of overweight and obesity in the midst of undergraduate medical pupils of West Bengal as well as to find out the association of overweight and or obesity with different hazardous factors.

\section{Material and Methods}

\section{Study design and the participants:}

This was a descriptive, observational, Institution based, epidemiological, cross-sectional study. The study participants were undergraduate medical pupils of $\mathbf{2}$ medical colleges of West Bengal; IPGME\&R and Midnapore Medical College.

\section{Data collection:}

The study was conducted from May 2011 to July 2011. A pre-designed pre-tested self-administered semi-structured questionnaire which contained both open-ended and closeended questions was used for data collection. The questionnaire was pre-tested on 20 pupils for its suitability and ease of use as well as the utility of the facts for analysis and necessary modifications were made. Before filling in the questions, the pupils were informed with reference to the study, their informed verbal consent were taken and were instructed to fill out the questionnaire completely and truthfully. All the persons were requested to fill the questions with their socio-demographic profiles (age, sex, religion, place of residence, type of family, per capita monthly income) and lifestyle factors like eating habits, smoking, alcohol consumption, time spent enjoying television, working with computer and doing physical activity. Examinations including height, weight were conducted of each participant with height measuring rod and weighing machine and BMI was calculated. Weight was measured using digital scale to the nearest of $0.5 \mathrm{Kg}$ with the person standing immobile on the weighing machine with feet $15 \mathrm{~cm}$ away from each other and weight evenly distributed on every leg in their light clothing without shoes. The weighing scale was regularly checked and calibrated with known standard weights at the commencement of each session of measurement. Digital Physician Scale was used for measuring height with an error to the nearest of $0.5 \mathrm{~cm}$ in bare feet and with the head in the Frankfurt plane keeping feet together, knees straight and backs of heels, buttocks and shoulder blades were in contact with the erect plane of the scale and height recording was done at the point when the measuring rod was quiescent on head. BMI (Body Mass Index) was calculated as the ratio of weight in $\mathrm{kg}$ to height in meter square, and were classified as underweight $(<18.5)$, normal range (18.5 - 24.9), overweight (25 - 29.9) and obese ( $\geq 30)$. 


\section{Inclusion criteria:}

Medical students who were willing to give informed consent in the age between 18 to 24 years of both sexes.

\section{Exclusion criteria:}

Medical students suffering from any chronic diseases e.g. Hypertension, Diabetes, Heart problems, Dyslipidaemia, Pregnancy, Students under some medications, e.g. oral contraceptive pills, anabolic steroids, Non-consenting students.

\section{Sample size calculation:}

Assuming the frequency of being overweight and obesity 49.4 percent based on a previous study, keeping the point of significance $(\alpha=0.05)$ and of marginal error 5 percent, the estimated sample size was calculated and it became 384 at 95 percent confidence interval ${ }^{9}$. The sample size was adjusted to 422, after allowing for the non-response error of 10 percent and other factors that decrease the yield of usable responses, an additional 38 subjects were included; 400 provided consent with a response rate of 94.79 percent. The list of total students was obtained using the students' register and the random number table was used for the selection of roll numbers in the study to meet up the necessary sample size. The simple random sampling technique was utilized to attain the required sample volume. If a designated student could not be contacted or was not cooperative during the three separate visits, the subject was considered as a non-respondent.

\section{Outcome Variable:}

Body mass index (BMI) was used to assess Obesity. Its predisposing factors were the socio-demographic profiles (age, sex, religion, type of family, per capita monthly income), dietary habits (type of diet, amount of soft drink consumed per week, daily intake of fast food, fruits and vegetables); family history of overweight; lifestyle issues like smoking, alcohol consumption, physical activity, time spent for watching television and computer work.

\section{Ethical committee approval:}

Necessary permission from the Institution was ensured and the research protocol was permitted by the Institutional Ethics Committee or Institutional Review Board of IPGME\&R as per declaration of Helsinki. Confidentiality, anonymity, respect and dignity were maintained throughout the study.

\section{Data management and statistical analysis:}

Data were analyzed using Epi-Info software. Occurrence of overweight and obesity was expressed as percentage. The demographic variables, eating habits, physical activities and other lifestyle related factors were compared between as Confidence Interval $(95 \% \mathrm{Cl})$ was assessed for each risk factor. All of the analyzed variables were tested using Chisquare tests as they were non-parametric. Two-tailed tests were considered for assessment of all $p$ values. Differences were well thought-out statistically noteworthy at $p$ value < 0.05 .

\section{Working Definitions:}

Non smoker: Non-smoker is a one who had never smoked in life; Occasional smoker: Occasional smoker is one who smokes less than once a week and or on special occasions; Regular smoker: Regular smoker is one who smokes daily; Current drinker: Current drinker is one who consumed any type of alcohol at an amount of one or more drinks in the preceding year; Physical activity: Other than routine daily activities, any type of vigorous or moderate activity for at least half an hour in a day for most of the days in a week. Fast food: Food that can be prepared and served very quickly. Examples are pizza, burger, rolls, samosa.

\section{Result:}

The age range of the participants was between 18 - 24 years. Majority (60.0\%) of them were more than 20 years, males (58\%), Hindus (93.7\%) and day-scholars (71.0\%). Most of them (82.5\%) belonged to nuclear families and 54.6 percent students had their per capita monthly income Rs $10,000.00$ to $30,000.00$. The general pattern of overweight (plump) and obesity to be calculated was 18.0 percent and 4.0 percent respectively according to BMI. [Table 1].

Table 1: Distribution of students' nutritional status according to Body Mass Index (BMI) (n=400)

\begin{tabular}{|c|c|c|}
\hline Nutritional status(BMI) & Number & Percentage \\
\hline Underweight $(<18.50)$ & 08 & 02.0 \\
\hline Normal range (18.50-24.99) & 304 & 76.0 \\
\hline Overweight/Pre-obese (25.00-29.99) & 72 & 18.0 \\
Obese ( $\geq 30)$ & 16 & 04.0 \\
Total & 400 & 100.00 \\
\hline
\end{tabular}

It was seen that the probable risk of being overweight and obesity was amplified with age, being significantly elevated (28.3\%) in higher age group ( $>20$ years) in comparison with the younger $(12.5 \%)$ age group $(\leq 20$ years) which was statistically significant. Among 232 males, 66 (28.5\%) were overweight and obese whereas among 168 females 22 (13.5\%) had overweight and obesity. With reference to the relation between obesity and sex, the outcome showed that occurrence of overweight and obesity was more common among male compared to females $(28.5 \%$ vs.13. $1 \%$ respectively). It was significantly associated [Table 2]. 


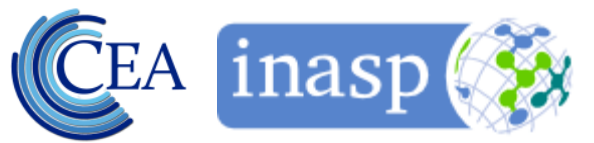

Table 2: Distribution of students' nutritional status concerning age and gender $(n=400)$

\begin{tabular}{|c|c|c|c|c|c|c|}
\hline & $\begin{array}{c}\text { BMI }<25 \\
\text { Number } \\
(\%) \\
\text { (Group 1) }\end{array}$ & $\begin{array}{c}\text { BMI } \geq \\
25 \\
\text { Numbe } \\
\text { r (\%) } \\
\text { (Group } \\
2 \text { ) }\end{array}$ & $\begin{array}{c}\text { Total } \\
\text { Number } \\
\text { (\%) }\end{array}$ & $\begin{array}{c}\text { Odds } \\
\text { Ratio } \\
\text { (95\% } \\
\text { CL) }\end{array}$ & $\begin{array}{c}\text { Chi } \\
\text { squa } \\
\text { re } \\
\left(x^{2}\right)\end{array}$ & $\begin{array}{c}p- \\
\text { value }\end{array}$ \\
\hline \multicolumn{7}{|c|}{ Age (years) } \\
\hline $\begin{array}{c}20 \text { and } \\
\text { less }\end{array}$ & $\begin{array}{c}140 \\
(87.5)\end{array}$ & $\begin{array}{c}20 \\
(12.5)\end{array}$ & $\begin{array}{c}160 \\
(100.0)\end{array}$ & \multirow{2}{*}{2.77} & 14.0 & \multirow{2}{*}{$<0.05$} \\
\hline $\begin{array}{c}\text { More } \\
\text { than } 20\end{array}$ & $\begin{array}{c}172 \\
(71.7)\end{array}$ & $\begin{array}{c}68 \\
(28.3)\end{array}$ & $\begin{array}{c}240 \\
(100.0)\end{array}$ & & 2 & \\
\hline \multicolumn{7}{|c|}{ Gender } \\
\hline Male & $\begin{array}{c}166 \\
(71.5)\end{array}$ & $\begin{array}{c}66 \\
(28.5)\end{array}$ & $\begin{array}{c}232 \\
(100.0)\end{array}$ & \multirow{2}{*}{0.38} & 13.3 & \multirow{2}{*}{$<0.05$} \\
\hline Female & $\begin{array}{c}146 \\
(87.0)\end{array}$ & $\begin{array}{c}22 \\
(13.0)\end{array}$ & $\begin{array}{c}168 \\
(100.0)\end{array}$ & & 8 & \\
\hline Total & $\begin{array}{c}312 \\
(78.0)\end{array}$ & $\begin{array}{c}88 \\
(22.0)\end{array}$ & $\begin{array}{c}400 \\
(100.0)\end{array}$ & & & \\
\hline
\end{tabular}

Normal = BMI <25; Overweight $/$ Obese $=\mathrm{BMI} \geq 25$;

Significance: alpha error was set at 0.05

Majority (82.5\%) of the students were not consuming vegetarian foods. More than one fourth of the respondents (28.0\%) took cold-drink in profound amount. Almost twothird of the subjects (61.5\%) were having fast and junk foods regularly. Overall only half of the study population (56\%) took fruits and vegetables in their daily life. Current smoking was reported by 20 percent of students, all of them were males. More than one-fourth (26.5\%) of students were regular consumers (all were males) of alcohol. For physical activity, only half of the study population (56.5\%) had habit of regular exercise. A total of 60.5 percent subjects used to watch TV and/computer for two hours or more daily. Among the overweight/obese subjects only 20.6 percent were non-vegetarian as compared to normal weight students where maximum i,e; 79.4 percent were non vegetarians and no significant relationship between BMI categories and type of diet was identified. Those consuming higher amount of soft drinks suffered significantly more from overweight and or obesity (53.6\%). The intake of fast food at least once daily by 27.6 percent of overweight/obese students as compared to 13.0 percent of those who did not take fast food daily had a significant positive relationship. Similar correlation was also observed between $\mathrm{BMI}$ and fruits/vegetables intake in the daily diet (12.5\% of overweight/obese against $87.5 \%$ of normal weight), alcohol consumption (58\% of overweight/obese against $48 \%$ of normal weight), habit of exercise $(9.7 \%$ of overweight/obese against $90.3 \%$ of normal weight) and duration of recreation in the form of watching television and or computer for two hours and more per day.

A statistically significant higher rate of obesity (38.0\%) was noted in those who were avoiding exercise. Smoking habit had no significant influence on body weight. A statistically significant association between BMI and duration of Television watching was seen where the proportion of overweight/obesity was higher (25.6\%) among those who watched TV for $\geq$ two hours/day compared with those students (16.5\%) who used to watch for $<2$ hours/day.
Pattern and determinants of overweight and obesity Table 3: Distribution of factors influencing body weight and their significance $(n=400)$

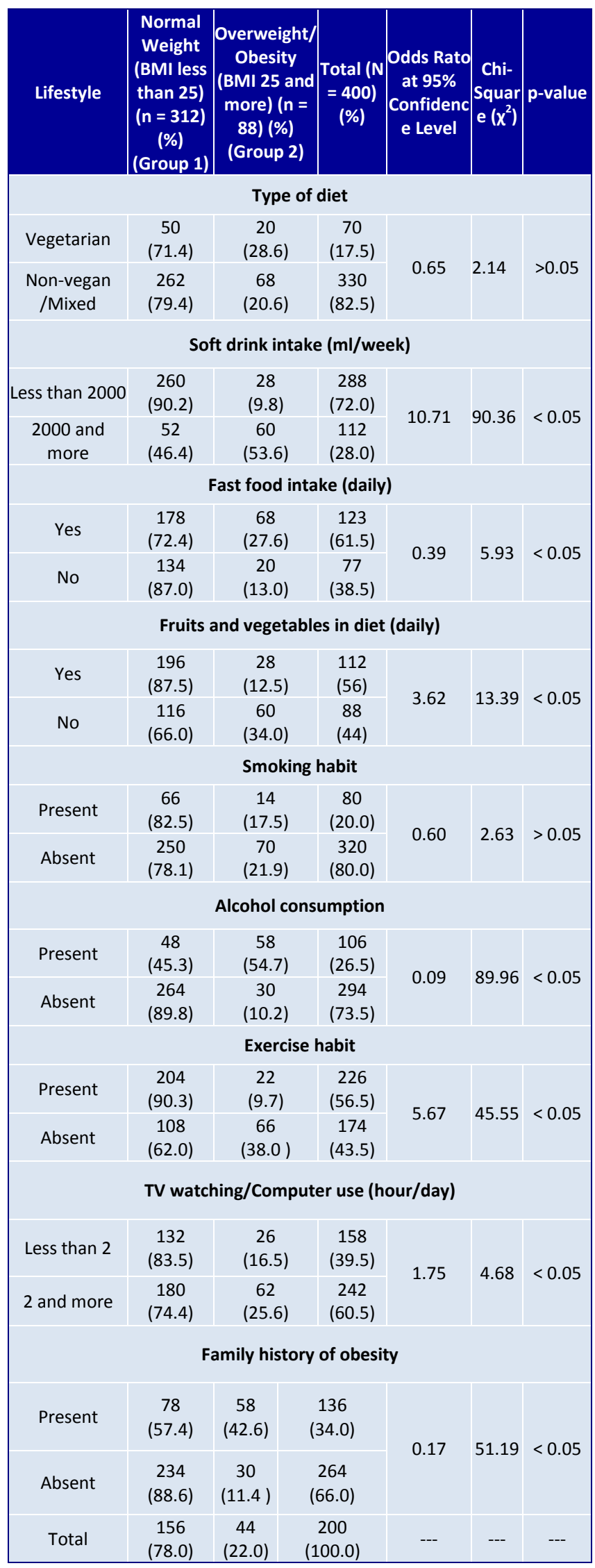

Significance: alpha error was set at 0.05 
Pattern and determinants of overweight and obesity Mahmood et al ${ }^{24}$ at Karachi (overweight and obesity $31.6 \%$ and $28.2 \%$ respectively)

A total of 34 percent students had positive family history obesity and students whose first degree relatives were overweight/obese $(42.6 \%)$ had a significantly higher risk of being obese regarding the mentioned group of students $(11.4 \%)$ with neither close relative being obese and the relation was statistically significant. [Table 3].

\section{Discussion:}

Obesity is caused by an interaction between the environmental factors, genetic predisposition, and human behaviour. Environment is likely to be major contributors to the obesity epidemic. Evidence supports the contribution of excess energy intake and decreased energy expenditure in this obesity epidemic. There is also evidence that the relative availability and price of different food products affect food consumption, that the built environment, such as quality of local parks, affects the level of physical activities of a community. These findings not only emphasize the impact of environment on the obesity epidemic but also indicate that policies affecting the availability of high-caloric-high-density food, the cost of foods, and the built environment may contribute to the obesity epidemic.

This was an observational, cross-sectional study in the midst of undergraduate medical pupils. The study subjects were mostly Hindus (93.7\%); belonged to nuclear families (82.5\%) and 54.6 percent students were from upper socio-economic status (per capita monthly income Rs 10,000.00 to $30,000.00)$. The study deserves discussion for the following issues. Obesity: Undergraduate medical students were assessed for the occurrence and correlates of overweight (plump) and obesity. A pattern of combined overweight (plump) and obesity was 22.0 percent (18\% overweight \& $4 \%$ obesie). These findings were comparable to some of those studies across different parts of the globe ${ }^{9-16}$. study by Gopalakrishnan et $\mathrm{al}^{9}$ at Malaysia revealed overweight accounted for 15.9 percent $\& 5.2 \%$ were found to be obese ;study by Joseph et al $^{10}$ at Thiruvanthapuram revealed 23.1 percent were overweight \& 1 percent were obese; gupta et $\mathrm{al}^{11}$ at Midnapore medical college calculated overweight to be 17.5 percent \& obesity 3.4 percent; Abdalla et al $^{12}$ at Khartoum found the pattern of overweight was 17.8 percent and obesity 9.2 percent; Al-Madani ${ }^{13}$ at Bahrain found that combined overweight \& obesity was 22.6 percent;. Boo et al ${ }^{14}$ at Malaysia found to be 30.1 percent ; Raza et al ${ }^{15}$ at Karachi revealed that 17.4 percent were overweight; Carter et al ${ }^{16}$ at United Arab Emirates found that 24 percent of students were overweight or obese; However, the pattern rate related to overweight and obesity was elevated than some other studies done among medical students ${ }^{17-20}$ by Aslam et al at ${ }^{17}$ at Karachi ( $9 \%$ ); by Chhabra et al ${ }^{18}$ at Delhi (11.7\%).; by Nojomi et al ${ }^{19}$ at Iran (12.4\% ); by Sinhababu et al ${ }^{20}$ at Bankura (5.1\%) On the contrary, the findings of this study were much lower compared with another group of studies conducted among comparable groups ${ }^{21-25}$ Bertisias et al ${ }^{21}$ at Greece ( $40 \%$ men and $23 \%$ women); Hingorjo et $\mathrm{al}^{22}$ at Karachi $(60.8 \%$ females and $44.4 \%$ males); Nisar et al ${ }^{23}$ at Karachi( $\left.41.7 \%\right)$;

\section{Age:}

The present study revealed that obesity among students aged less than 20 years were 12.5 percent in comparison with 28. 3 percent in the upper age group which was statistically significant. These findings were comparable with some previous studies conducted among medical students of Sudan ${ }^{12}$ and University students of $\operatorname{Iran}^{19}$ However a study at Karachi showed no association with age 23

\section{Sex / Gender:}

This study showed a significantly higher rate of overweight and obesity among males in comparison with females across ages (28.5\% versus $13.0 \%$ ) that can be explained by the fact that females are more careful about their mass due to their perceptions to be slim from the strong impact of the mass media on girl's body shape and image perception. This was consistent with findings of several studies among medical students ${ }^{8,10-12,14,17,21,24}$. On the contrary, reverse findings were also noted in other studies ${ }^{19,22}$.

\section{Dietary habits:}

In our study type of diet was not found to have significant role on body weight which was corroborative with previous studies at Midnapore and at Gujarat ${ }^{11,25}$.

\section{Amount of soft drink consumed per week:}

It was observed that the participants who took a big amount of soft drinks were affected further from obesity and overweight than persons who took a lesser amount and the relation was statistically significant which was in agreement with studies by Abdalla et al at Khortum ${ }^{12}$, Boo et al at Malaysia ${ }^{14}$ and Nisar et al at Karachi ${ }^{23}$.

\section{Daily intake of fast food:}

The effect on weight status of higher intake of junk and quick food due to its deliciousness, accessibility and convenience was also observed. It was observed that the proportion of overweight was about six times more among those subjects who were consuming junk and fast food more frequently and the difference was statistically significant in line with a study among dental and medical students of Karachi (up to four times higher), in post graduate doctors of Karachi (five times higher), in Kuwait (three times higher), also in Gwalior city, Bankura, Kerala and Gujarat from India 20,22, 23, 24. Fruits and vegetables: It was noted that overweight was more prevalent among those who were consuming fruits and vegetables less frequently showing a significant correlation between BMI in one side and vegetables and fruits utilization in other side. Fruits and vegetables play their role in increasing general health and is inversely associated to total and low density lipoprotein cholesterol and with risk of obesity. Thus there was a negative association between vegetable intake and overweight status which was statistically significant. 


\section{Pattern and determinants of overweight and obesity Limitation of the study}

Lifestyle issues:

Study supported that increase in BMI was more expected to be contributed by consumption of alcohol, foods little in fibre, use of caffeine and consuming cruciferous vegetables. Alcohol consumption was found to have a positive association with BMI that was similar to few studies, but dissimilar to other studies where drinking was inversely associated with obesity due to over consumption of alcohol with proper amount of food ${ }^{11}$. In this study, smoking was associated with low BMI and being smoker was not associated to have noteworthy role on body weight which was corroborative to some other studies. Cigarette smokers tend to have low weight as compared to no smokers and exsmokers ${ }^{11,14}$. Physical inactivity was significantly associated with overweight and obesity which was also in accordance with previous studies ${ }^{11,22-24}$. Physical activity improves corporal fitness, decreases the risk of persistent diseases and disability and helps avoid unhealthy weight increase. Exercise programme to dietary control can uphold greater reduction in weight than change in food or physical doings on its own. Physical doings of doctors and future doctors are important from a individual point of view as well as it influences the counselling of their clients.

In this study, significant finding for obesity was long time spent using computer and or television watching that was in agreement with several other studies, where television viewing and or computer use were positively associated with obesity. This can be partially narrated by the food and beverage utilization during television enjoyment ${ }^{9,22}$. Similarly family record of obesity was also observed to be related with overweight and obesity in this study which was statistically significant and consistent with prior studies ${ }^{10,24 \text {, }}$ 25

\section{Conclusion}

This study suggested a towering occurrence of hazardous factors among medical students of West Bengal and almost one-quarter of undergraduate medical students were with over-weight and obesity. The main factors for way of life responsible for obesity were found longer time spent by means of computer/ watching television, large amount of soft drink intake, daily fast and junk food consumption, fruits and vegetables taken infrequently, physical inactivity, being non-smoker and addiction to alcohol. Also, increasing age, male gender and positive family history play a role for obesity development.

\section{Recommendation}

Due to their sedentary life style the health care personnel were found susceptible to be overweight or obese and in due course are at a bigger risk for persisting diseases. As student group in medicine is the future health service professionals it is crucial that they should have appropriate wakefulness and alertness concerning obesity and obesity linked disorders. Up-gradation in way of life in beginning years of medical course would construct future physicians who will be changing behavior in practice and promotion for healthy diet and active way of life.
The study group was small. Analysis of the influence of all modifiable risk factors e,g; stress was not done. The diet intake and energy utilized was not quantified.

\section{Relevance of the study:}

This study suggests that overweight (plump) and obesity were found prevalent amongst medical students of one of medical colleges of Kolkata. This study can be repeated in the adjacent areas and states of our country to determine a national representative database. Study findings can be utilized to protect our future physicians from overweight and obesity. What this study added: Overweight and obesity is a present day problem. This was 22 percent in this study. Increasing age, nuclear family, non-vegetarian diet and junk food, sedentary life and family history of obesity are more likely associated factors for overweight and obesity.

\section{Author's Contribution:}

All the authors were involved in designing the study, collecting and compiling the data, $\mathrm{MB}$ and $\mathrm{PD}$ did the analysis of data, were involved in the data interpretation, drafted the manuscript. Manuscript was revised by all. All the authors approved the final document.

\section{Acknowledgements:}

The authors are thankful to the medical students and authority of medical colleges (IPGMER and Midnapore Medical College)..

\section{Conflict of interest:}

There is no conflict of interest among authors arising from the study.

\section{References:}

1. World Health Organization, Media centre, Obesity and overweight, Fact sheets, Updated March 2011.

2. World Health Organization. Obesity: preventing and managing the global epidemic. Report of a WHO consultation. World Health Organ TRS 2000;894;1-253.

3. World Health Organization, Geneva. Diet, Nutrition and the prevention of chronic diseases. Technical Report Series 2003;916.

4. Heitman BL. Ten-year trends in overweight and obesity among Danish men and women aged 30-60 years. Int J Obes Relat Disord. 2000;24(10):1347-52. http://dx.doi.org/10.1038/sj.ijo.0801388

5. U.S. Department of Health and Human Services. The Surgeon General's Call to Action to Prevent and Decrease and obesity 2001.

6. WHO | Obesity and overweight [Internet]. WHO. [cited 2014 Jan 29]. Available from: http://www.who.int/mediacentre/factsheets/fs311/en/

7. International Institute for Population Sciences. Mumbai. Ministry of Health \& Family Welfare, Government of India. August 2009; volume 1: pp 14-5, 43-48, 303-8. 
8. Kumar A, Ramiah S. Anthropometric studies on students of the Nepal Medical College: elbow breadth. Kathmandu Univ Med J (KUMJ). 2005;3(4):345-8.

9. Gopalakrishnan S, Ganeshkumar P, Prakash MV, Christopher, Amalraj V. Pattern of overweight/obesity among the medical students, Malaysia. The Medical Journal of $\quad$ Malaysia $2012 ;(4): 442-44$. PMid:23082463

10. Joseph A, Mohan AS, Arathy R, Deb Barma A, Varghese S. Pattern of obesity among students in government medical college, Thiruvananthapuram. Undergraduate Research Papers- 2006.

11. Gupta S, Ray TG, Saha I. Overweight, obesity and influence of stress on body weight among undergraduate medical students. Indian J Community Med 2009;34(3):2557.

http://dx.doi.org/10.4103/0970-0218.55296

PMid:20049308 PMCid:PMC2800910

12. Abdalla SM, Mohamed EY. Obesity amomg medical students of the National Ribat University, Khartoum 2008. Sudan. J. Public Health 2010;5(2):16-9.

13. Al-Madani KM. Obesity among Medical Practitioners and Medical Students in Bahrain. Short Communication. Bahrain Med Bull. 2000;22(30):1-3.

14. Boo NY, Chia GJQ, Wong LC, Chew RM, Chong W, Loo RCN. The pattern of obesity among clinical students in a Malaysian medical school. Singapore Med J.2010; 51(2):126-2.

\section{PMid:20358151}

15. Raza S, Sheikh MA, Hussain MF, Siddiqui SE, Muhammad R, Aziz $S$ et al.Dietary modification, body mass index (BMI), blood pressure (BP) and cardiovascular risk in medical students of a government medical college of Karachi. J Pak Med Assoc. 2010; 60(11):970-4. PMid:21375210

16. Carter AO, Elzubeir $M$, Abdulrazzaq $Y M$, Revel $A D$, Townsend A. Health and lifestyle needs assessment of medical students in the United Arab Emirates. Med Teach 2003;25(4):

492-6.

http://dx.doi.org/10.1080/01421590310001605633

PMid:14522670

17. Aslam F, Mahmud H, Waheed A. Cardiovascular health behaviour of medical students in Karachi. J Pak Med Assoc. 2004;54:492-5.

PMid:15518377

18. Chhabra P, Grover VL, Aggarwal K, Kannan AT. Nutritional Status and Blood Pressure of Medical Students
19. Nojomi M, Najamabadi S. Obesity among university students, Tehran, Iran. Asia Pac J Clin Nutr. 2006;15(4):51620.

\section{PMid:17077068}

20. Sinhababu A. Body Mass Index status and some obesity promoting dietary factors among students of Nursing Training School, Bankura. Indian J Community Med. 2006;31(2):78-80.

21. Bertsias G, Mammas I, Linardakis M, Kafatos A. Overweight and obesity in relation to cardiovascular disease risk factors among medical students in Crete, Greece. BMC Pub Hlth. 2003;3:3. http://dx.doi.org/10.1186/1471-2458-3-3

PMCid:PMC140012

22. Hingorjo MR, Syed S, Qureshi MA.Overweight and obesity in students of a dental college of Karachi: lifestyle influence and measurement by an appropriate anthropometric index. J Pak Med Assoc. 2009;59(8):528-32. PMid:19757698

23. Nisar N, Qadri MH, Fatima K, Perveen S. Dietary habits and life style among the students of a private medical university Karachi. J Pak Med Assoc. 2009;59(2):98-1. PMid:19260574

24. Mahmood S,Najjad MK,Ali N, Yousuf N, Hamid Y. Predictors of obesity among post graduate trainee doctors working in a tertiary care hospital of public sector in Karachi, Pakistan. J Pak Med Assoc.2010;60(9):758-61. PMid:21381586

25. Chhaya S, Jadav P. Dietary and lifestyle pattern in relation to overweight and obesity among the medical and nursing students. The Indian Journal of Research and Reports in Medical Sciences 2012;2(3):9-12.

\begin{tabular}{|c|c|}
\hline \multicolumn{2}{|c|}{ Article Information } \\
\hline \multicolumn{2}{|c|}{ Article history } \\
\hline Received & $2^{\text {nd }}$ September 2013 \\
\hline Received in revised form & $20^{\text {th }}$ March 2014 \\
\hline Accepted & $24^{\text {th }}$ March 2014 \\
\hline
\end{tabular}

